found impressions of ginkgo similar leaves with on the one hand a great similarity with the known members of the genus Kerpia (Kerpia macroloba and Kerpia belebeica), but on the other hand they are clearly not identical to this representative at the species level. According to the results of the study of these impressoins in 2014 we described a new species of the genus Kerpia - Kerpia samarica N.S. Bukhman et L.M. Bukhman, 2014. In this paper we give description of both known and new findings of species Kerpia samarica and a comparison of this species with other species of the genus Kerpia.

Keywords: paleobotany; Permian System; Kazanian stage; Angarida; Western Subangarida; Samara region; Novyi Kuvak location; ginkgoaceae; ginkgophyta; preginkgophyta; psygmophyllaceae; Kerpia; Kerpia macroloba; Kerpia belebeica; Kerpia samarica; Ginkgophyllum; Psygmophyllum.

\title{
УДК 599.323.23
}

\section{РЕПРОДУКТИВНАЯ АКТИВНОСТЬ САМЦОВ ПОЛЧКА (GLIS GLIS L., 1766) В ПЕРИФЕРИЧЕСКОЙ ПОПУЛЯЦИИ}

(C) 2016

В.А. Вехник, кандидат биологических наук, научный сотрудник

Жигулёвский государственный природный биосферный заповедник им. И.И. Спрыгина, Жигулёвск (Россия)

Аннотаџия. Полчок - дендробионтный зимоспящий грызун, размножающийся один раз в год. Характерной особенностью биологии сони служит регулярное подавление размножения в неурожайные годы. В центре ареала оно обусловлено отсутствием репродуктивной активности самцов. В исследованной популяции на восточной периферии ареала вида предыдущими исследованиями доказана определяющая роль в этом процессе массовой резорбции эмбрионов у самок. Динамика репродуктивной активности самцов и ее влияние на репродукцию ранее подробно не рассматривались. В данной работе исследованы периодичность и интенсивность репродуктивной активности самцов в зависимости от возраста и фазы популяционного цикла. Ежегодно наблюдалась репродуктивная активность подавляющего большинства самцов, доля не участвующих в размножении особей не превышала 6,7\%. Выявлены возрастные отличия в сроках вступления в размножение: первыми приходили в состояние активности годовалые и двухлетние самцы, после них - трехлетние и более старшие. Минимальная продолжительность периода спариваний была отмечена у годовалых самцов, максимальная - у двухлетних, для которых были характерны также самые продолжительные индивидуальные сроки репродуктивной активности. Вследствие резких колебаний возрастной структуры популяции именно двухлетние самцы имеют наибольшее значение в репродукции, однако трехлетние и более старшие самцы в урожайные годы также способны обеспечить воспроизводство популяции. Выявлена характерная особенность репродукции годовалых самцов: они вступали в размножение в зависимости от массы тела. Колебания репродуктивной активности самцов в течение активного периода значительной роли в регуляции воспроизводства не играют. Меньшая продолжительность репродуктивной активности годовалых самцов в годы подавления размножения компенсируется более поздним вступлением в размножение трехлетних и более старших особей. Несинхронное участие в размножении самцов разных возрастных групп обеспечивает размножение максимального числа особей.

Ключевые слова: полчок; соня; Glis glis; репродуктивная активность самцов; массовая резорбция; репродукция; подавление размножения; Жигулёвская возвышенность; периферическая популяция; возрастная структура.

Постановка проблемы в общем виде и ее связь с важными научными и практическими задачами. Исследования размножения имеют фундаментальное значение для сохранения видов, популяций и экосистем в целом и являются научной основой высокотехнологичных подходов к охране природы, в том числе реинтродукции животных в естественную среду и искусственного разведения в неволе. Соневые один из древнейших и малоизученных подотрядов грызунов среди таксонов неморальных европейских млекопитающих. Все 26 видов сонь мировой фауны включены в списки международных природоохранных документов - Красную Книгу МСОП и Бернскую Конвенцию по сохранению естественных местообитаний европейской фауны [1]. Соня-полчок (Gliridae, Rodentia) более других видов привязана к старовозрастным широколиственным лесам [2], и, следовательно, ее ареал подвержен сильным изменениям из-за антропогенной трансформации естественных местообитаний. На Жигулёвской возвышенности в настоящее время сохранилась популяция полчка на восточном пределе распространения. Изучение внутрипопуляционных механизмов регуляции размножения служит необходимой научной базой стратегии сохранения вида в естественной среде обитания и разработки природоохранных мер, препятствующих дальнейшему сокращению его численности до опасной черты. В свою очередь, интенсивность размножения свидетельствует об оперативном состоянии популяции и тенденциях его изменения.

Полчок - самый крупный вид сонь, дендробионтный зимоспящий грызун, ведущий ночной образ жизни. Размножение вида происходит один раз в год. На всем протяжении ареала фиксируются отдельные годы полного отсутствия размножения или снижения его интенсивности до минимального числа детенышей. Ранее исследованы структура эстрального цикла и механизм подавления размножения сони в неблагоприятные годы [3]. Влияние репродуктивной активности самцов на интенсивность размножения на 
Вехник В.А.

Репродуктивная активность самцов полчка (Glis glis L., 1766).

03.02 .00 - общая биология

российской территории не рассматривалось, в то время как в работах исследователей Центральной и Западной Европы ей отводится центральная роль в воспроизводстве популяции. В данной работе проанализированы данные по репродуктивной активности самцов полчка в годы массового размножения и его подавления и выявлены возрастные закономерности.

Анализ последних исследований и публикаџий, в которых рассматривались аспекты этой проблемы и на которых основывается автор; выделение не разрешенных ранее частей общей проблемы.

В настоящее время репродуктивная биология полчка изучается преимущественно в странах Центральной и Западной Европы - в оптимуме ареала вида [4-7]. В ряде публикаций описывается явление подавления размножения сонь и его связь с урожайностью бука [8-17]. Механизм регуляции размножения вида в оптимуме ареала подробно изучен. В репродуктивно успешные годы детеныши появляются в августе-сентябре, за месяц-два до плодоношения бука (Fagus sylvatica) - основного источника корма полчка, и таким образом выход молодых зверьков из гнезд синхронизирован с периодами максимальной доступности пищи. Регуляция размножения сонь основана на репродуктивной активности самцов: в неурожайные для бука годы в начале сезона активности у них отсутствует сперматогенез, поэтому спариваний не происходит и детеныши не рождаются. Триггерным фактором, стимулирующим рост семенников, является обилие цветков и бутонов бука весной и в начале лета [18; 19].

Исследования биологии полчка вне зоны распространения бука проводились преимущественно на территории бывшего СССР, но подавление размножения детально не рассматривалось [20-24]. В настоящее время исследователи Латвии и Литвы подробно изучают экологические особенности вида на северной границе ареала, однако репродуктивная регуляция здесь пока до конца не выяснена [25-27]. Таким образом, репродуктивная биология полчка в пессимуме ареала оставалась неисследованной. Нашими предыдущими исследованиями показано, что в целом в жигулёвской популяции ежегодно наблюдается репродуктивная активность самцов и беременность большинства самок, но в неблагоприятные годы происходит массовая резорбция эмбрионов [3]. Изучение репродуктивной активности самцов полчка на Жигулёвской возвышенности послужило моделью выяснения соотношений репродуктивного вклада самцов и самок в периферической популяции.

Формирование челей статьи (постановка задания). Исследование периодичности и интенсивности репродуктивной активности самцов полчка в зависимости от возраста на разных фазах популяционного цикла.

Изложение основного материала исследования с полным обоснованием полученных научных результатов.

Полевые исследования проводились на территории Жигулёвского заповедника с 2005 по 2011 гг. на 6 стационарных и 10 пробных учетных линиях методом мечения и повторных отловов. Полчков отлавливали металлическими живоловками, установленными на деревьях в линию по 20 штук на высоте 1,5-2 м примерно в 10 м друг от друга. Всех отловленных животных метили индивидуальными татуировками на ушных раковинах. По пропорциям тела и окраске идентифицировали три возрастные категории полчков: годовалые (перезимовавшие один раз, 913 месяцев), двухлетние (перезимовавшие два раза), трехлетние и более старшие. При повторных отловах возраст зверьков точно определяли по татуировкам. В общей сложности был проведен анализ репродуктивной активности 262 перезимовавших половозрелых самцов.

Подробные исследования репродуктивного состояния полчков проводили на протяжении всего сезона активности с мая по сентябрь в год успешного размножения (2007) и в течение двух неблагоприятных лет (2008 и 2011). Репродуктивную активность самцов определяли по величине и окраске семенников. Значительная часть животных была отловлена только в начале либо в конце сезона активности, и установить их участие в размножении не представлялось возможным.

Сони становятся половозрелыми на следующий год после первой зимовки и сохраняют способность давать потомство только один раз в год на протяжении всей жизни. Репродуктивный цикл полчков в Жигулях продолжается в течение всего активного сезона взрослых особей с июня по август и включает гон, беременность и лактационный период после рождения детенышей. Самцы выходят из состояния гибернации одновременно с самками либо на неделю раньше в конце мая - начале июня. Часть самцов готовы к спариванию сразу, остальные - через несколько дней после спячки. Почти все самки выходят из спячки в фазе эструса. Подавляющее большинство особей участвуют в спаривании, тип половых отношений - промискуитет. Сразу после спаривания самки прогоняют самцов. Большинство самок в конце июня беременны. В репродуктивно успешные годы массовое рождение детенышей происходит в начале августа. Лактационный период продолжается примерно сорок дней. После распада выводков в начале сентября самки залегают в спячку. Взрослые самцы впадают в спячку на неделю раньше - в конце августа.

Вследствие нерегулярного размножения наблюдались значительные колебания возрастной структуры популяции (рис. 1). В 2005 и 2007 - годах массового рождения молодняка - в возрастной структуре значительно доминировали двухлетние особи и практически отсутствовали годовалые. В 2006 и 2008 годах подавления размножения - наоборот, доминировали годовалые зверьки, а доля двухлетних была очень низкой. В 2009 г. были отловлены только двухи трехлетние и более старшие самцы, доминировали двухлетние, т.к. наблюдался второй год репродуктивной паузы подряд. В 2010 году, после двух лет репродуктивной паузы, абсолютное большинство популяции составляли трехлетние и более старшие особи. После их успешного размножения в 2011 г. в популяции доминировали годовалые самцы.

В течение всего периода полевых наблюдений репродуктивного состояния полчков в Жигулях ежегодно наблюдалась репродуктивная активность подавляющего большинства самцов (табл. 1). 


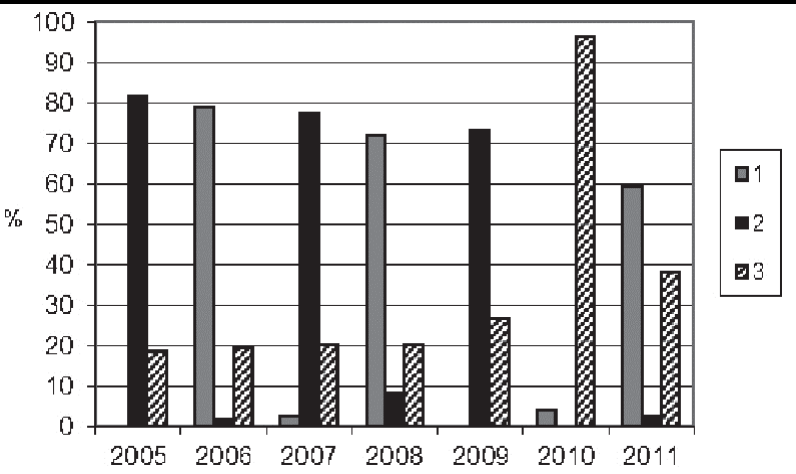

Рисунок 1 - Возрастная структура самцов полчка в популяции Жигулёвской возвышенности в 2005-2011 гг. (исключая сеголеток).

1 - доля годовалых, 2 - доля двухлетних,

3 - доля трехлетних и более старших самцов

Таблица 1 - Репродуктивная активность самцов полчка в жигулёвской популяции в 2005-2011 гг.

\begin{tabular}{|l|c|c|}
\hline Год & $\begin{array}{c}\text { Доля активных } \\
\text { самцов, } \%\end{array}$ & $\begin{array}{c}\text { Доля неактивных } \\
\text { самцов, } \%\end{array}$ \\
\hline 2005 & 74,1 & 0 \\
\hline $2006^{*}$ & 71 & 3,2 \\
\hline 2007 & 87,5 & 0 \\
\hline $2008^{*}$ & 61,5 & 5,4 \\
\hline $2009^{*}$ & 57,1 & 6,7 \\
\hline 2010 & 92,6 & 3,7 \\
\hline $2011^{*}$ & 67,0 & 0 \\
\hline \multicolumn{2}{|c|}{ * Годы подавления размножения } \\
\hline
\end{tabular}

В годы подавления размножения репродуктивная активность самцов была достоверно более низкой $\left(\chi^{2}\right.$ $=7,7, d f=1, p<0,01)$, что определялось чередованием возрастной структуры популяции: если в репродуктивно успешные годы в популяции значительно преобладали взрослые двухлетние самцы, то в годы подавления размножения преобладали годовалые особи, не окончившие рост, и соответственно их периоды активности были короче.

В репродуктивно успешном 2007 г. максимальная репродуктивная активность самцов наблюдалась во второй половине июня - в июле и в августе постепенно затухала (рис. 2). В годы подавления размножения - 2008 и 2011 гг. - интенсивность репродуктивной активности была выше, однако продолжительность ее несколько сократилась (рисунки 3, 4). Период максимальной активности в 2008 г. наблюдался в июне, в 2011 г. - в конце июня-начале июля. Более ранние сроки гона самцов в 2008 и 2011 гг. также связаны с их возрастом: подавляющее большинство составляли годовалые особи, пробуждение которых обычно наблюдается раньше, чем двух- и трехлетних, в связи с меньшим объемом жировых запасов.

Самцы вступали в размножение не синхронно в зависимости от возраста: первыми приходили в состояние активности годовалые и двухлетние самцы, после них - трехлетние и более старшие самцы. Наименьшей продолжительностью периода спариваний характеризовались годовалые самцы, впервые участвующие в размножении. Дольше всего в размножении участвовали двухлетние самцы (табл. 2).

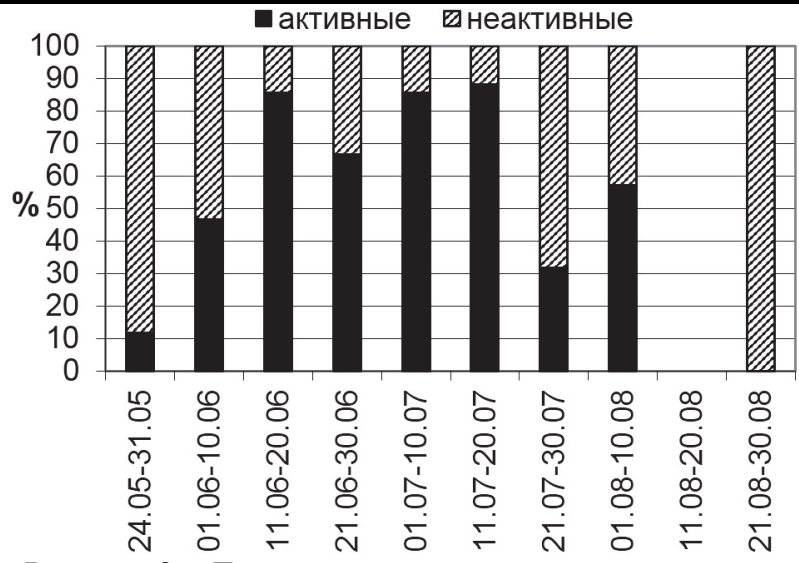

Рисунок 2 - Динамика репродуктивной активности самцов в жигулёвской популяции полчков в 2007 г. По оси ординат - доля самцов в отловах за 10 дней

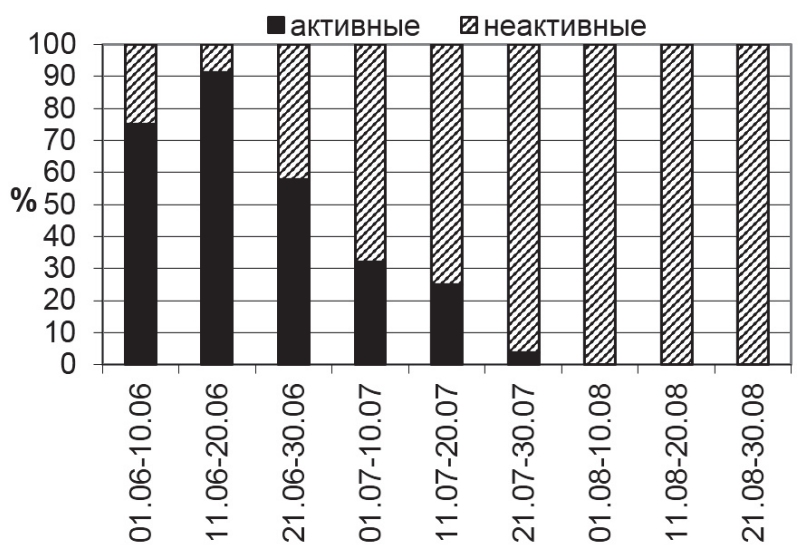

Рисунок 3 - Динамика репродуктивной активности самцов в жигулёвской популяции полчков в 2008 г. По оси ординат - доля самцов в отловах за 10 дней

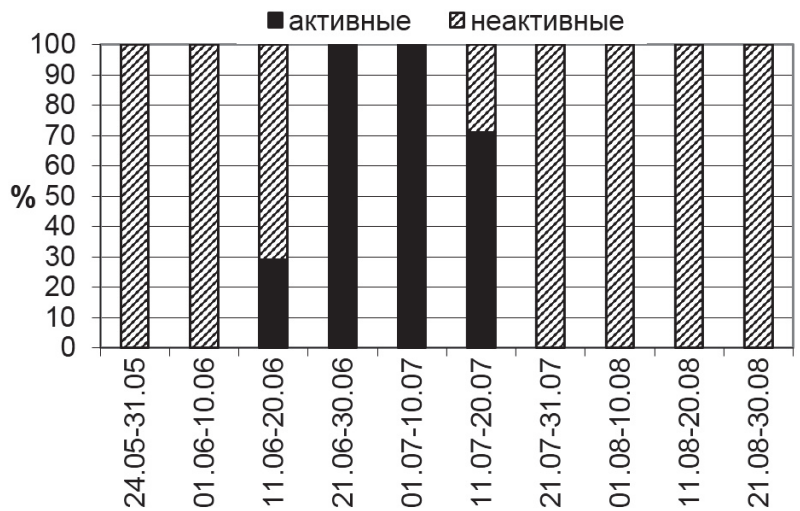

Рисунок 4 - Динамика репродуктивной активности самцов в жигулёвской популяции полчков в 2011 г. По оси ординат - доля самцов в отловах за 10 дней

Таблица 2 - Крайние даты отловов репродуктивно активных самцов разных возрастных групп на Жигулёвской возвышенности в 2005-2008 гг.

\begin{tabular}{|c|c|c|c|c|c|c|}
\hline \multirow{2}{*}{$\begin{array}{l}\text { Год/ } \\
\text { во3- } \\
\text { раст }\end{array}$} & \multicolumn{2}{|c|}{1 год } & \multicolumn{2}{|c|}{2 года } & \multicolumn{2}{|c|}{$\begin{array}{c}3 \text { года } \\
\text { и старше }\end{array}$} \\
\hline & $\begin{array}{l}\text { пер- } \\
\text { вый }\end{array}$ & $\begin{array}{c}\text { послед- } \\
\text { ний }\end{array}$ & $\begin{array}{l}\text { пер- } \\
\text { вый }\end{array}$ & $\begin{array}{c}\text { послед- } \\
\text { ний }\end{array}$ & $\begin{array}{l}\text { пер- } \\
\text { вый }\end{array}$ & $\begin{array}{c}\text { послед- } \\
\text { ний }\end{array}$ \\
\hline 2007 & - & - & 31.05 & 05.08 & 10.06 & 04.08 \\
\hline 2008 & 02.06 & 16.07 & - & - & 14.06 & 25.07 \\
\hline 2011 & 15.06 & 22.07 & - & - & 08.07 & 18.07 \\
\hline
\end{tabular}


Вехник В.А.

Репродуктивная активность самцов полчка (Glis glis L., 1766)...

03.02.00 - общая биология

При сравнении индивидуальных сроков репродуктивной активности в год массового размножения и в годы подавления размножения самые длительные периоды возможных спариваний также отмечались у двухлетних самцов (табл. 3).

Таблица 3 - Максимальные индивидуальные периоды репродуктивной активности самцов на Жигулёвской возвышенности в 2007, 2008 и 2011 гг. (количество дней)

\begin{tabular}{|l|c|c|c|}
\hline \multicolumn{1}{|c|}{ Возраст } & 2007 год & 2008 год & 2011 год \\
\hline 1 год & - & 33 & 34 \\
\hline 2 года & 48 & - & - \\
\hline 3 года и старше & 39 & 29 & - \\
\hline
\end{tabular}

Выявлена характерная особенность репродукции годовалых самцов: они принимали участие в размножении в зависимости от массы тела. Кроме достоверных отличий, выявленных при ее сравнении, эта зависимость была прослежена при использовании модели логистической регрессии: в 2006 г. $\chi^{2}=15,4$, p $<0,001$ (рис. 5); в 2008 г. $\chi^{2}=10,1, \mathrm{p}=0,001$, в 2011 г. $\chi^{2}=6,26, p=0,012$.

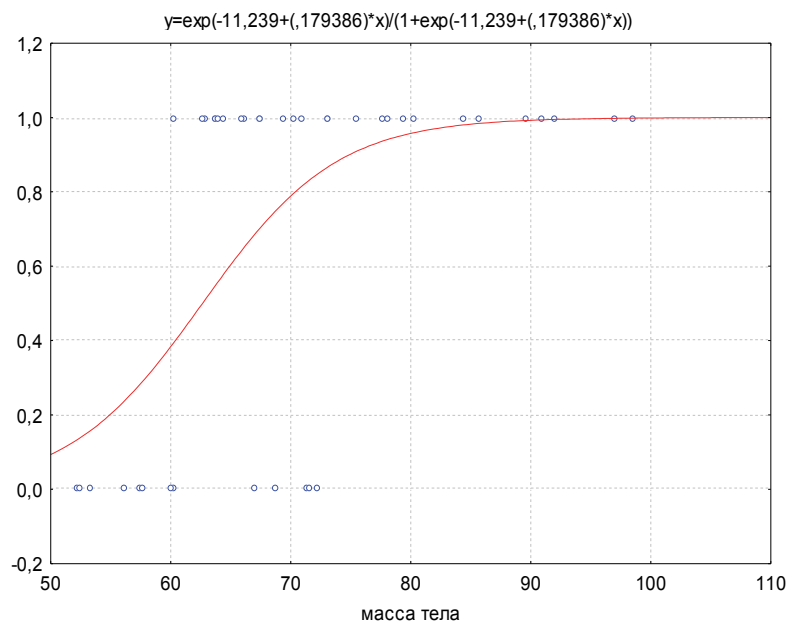

Рисунок 5 - Зависимость участия в размножении годовалых самцов от массы тела в 2006 г. в жигулёвской популяции. Модель логистической регрессии

Так как подобной связи у других возрастных групп достоверно отмечено не было, то можно утверждать, что здесь основную роль играют не энергетические запасы, а возраст зверьков. Период рождения детенышей в жигулёвской популяции составляет около месяца, и именно дата рождения определяет массу тела годовалых самцов на следующий год и время вступления в размножение.

Выводы исследования и перспективы дальнейших изысканий данного направления. Анализ репродуктивной активности самцов сонь на периферии ареала убедительно показал достаточный уровень репродуктивной активности полчков для ежегодного участия в размножении. Основную роль в воспроизводстве популяции играют двухлетние самцы, для которых характерны максимальные периоды индивидуальной репродуктивной активности и длительность гона в целом. В то же время, в годы подавления размноже- ния меньшая продолжительность репродуктивной активности годовалых самцов компенсируется более поздним вступлением в размножение трехлетних и более старших самцов. Несинхронное участие в спариваниях самцов разных возрастных групп обеспечивает участие максимального числа особей в размножении. Кроме того, длительный период гона, составляющий более половины активного периода сонь, нивелирует влияние негативных внешних условий на интенсивность репродуктивных процессов. Такая особенность в размножении имеет приспособительное значение для зимоспящих животных с коротким сезоном активности и нерегулярным размножением.

Таким образом, колебания репродуктивной активности самцов в течение активного периода значительной роли в регуляции воспроизводства не играют. Проведенные исследования подтвердили определяющее значение резорбции эмбрионов в регуляции размножения периферической популяции, в отличие от популяций Центральной Европы, где механизм внутрипопуляционной регуляции полностью зависит от репродуктивной активности самцов. Это подтверждает общую закономерность функционирования периферических популяций, согласно которой в экстремальных условиях периферии ареала наблюдаются менее совершенные механизмы регуляции популяционного гомеостаза [28]. Подобная пластичность репродуктивных стратегий у одного вида раскрывает широкие перспективы экспериментальных исследований регуляции размножения и увеличивает потенциальное значение изучения промежуточных форм механизма внутрипопуляционной регуляции полчка.

\section{СПИСОК ЛИТЕРАТУРЫ:}

1. Kryštufek B., Haberl W. Dormouse associations in Slovenia - a new approach to an old tradition // Trakya University Journal of Scientific Research. 2001. V. 2. № 2. P. 171-177.

2. Россолимо О.Л., Потапова Е.Г., Павлинов И.Я., Крускоп С.В., Волцит О.В. Сони (Муохіdaе) мировой фауны. М.: Изд-во МГУ, 2001. 229 с.

3. Вехник В.А. Массовая резорбция как авторегуляторный механизм цикличности размножения сониполчка (Glis glis L., 1766) на периферии ареала // ДАН. 2010. Т. 435 (3). С. 414-416.

4. Jurczyszyn M., Zgrabczyńska E. Influence of population density and reproduction on space use and reproduction on space use and spatial relations in the edible dormouse // Acta theriol. 2007. V. 52 (2). P. 181-188.

5. Hürner H., Kryštufek B., Sarà M., Ribas A., Ruch T., Sommer R., Ivashkina V., Michaux J. Mitochondrial phylogeography of the edible dormouse (Glis glis) in the western Palearctic region // J. Mamm. 2010. V. 91. P. 233-242.

6. Kryštufek B. Glis glis (Rodentia: Gliridae) // Mammalian species. 2010. V. 42. P. 195-206.

7. Hoelzl F., Bieber C., Cornils J.S., Gerritsmann H., Stalder G.L., Walzer C., Ruf T. How to spend the summer? Free-living dormice (Glis glis) can hibernate for 11 month in non-reproductive years // J. Comp. Physiol. B. 2015. V. 185. P. 931-939.

8. Bieber C. Sexual activity and reproduction in three feral subpopulations of the fat dormouse // Nat. Croatica. 1997. V. 6 (2). P. 205-216. 
9. Bieber C. Population dynamics, sexual activity and reproduction failure in the fat dormouse (Myoxus glis). // J. Zool. (London). 1998. V. 244. P. 223-229.

10. Schlund W., Scharfe F., Ganzhorn J. U. Longterm comparison of food availability and reproduction in the edible dormouse (Glis glis) // Mammalian Biology. 2002. V. 67. P. 219-232.

11. Kryštufek B., Zavodnik M. Autumn population density of the edible dormouse (Glis glis) in the mixed montane forest of Central Slovenia over 33 years // Acta Zool. Academiae Scientiarum Hungaricae. 2003. V. 49 (1). P. 99-108.

12. Pilastro A., Marin G., Tavecchia G. Long living and reproduction skipping in the fat dormouse // Ecology. 2003. V. 84. P. 1784-1792.

13. Fietz J., Schlund W., Dausmann K.H., Regelmann M., Heldmaier G. Energetic constraints on sexual activity in the male edible dormouse // Oecologia. 2004. V. 138. P. 202-209.

14. Ruf T., Fietz J., Schlund W., Bieber C. High survival in poor years: life history tactics adapted to mast seeding in the edible dormouse // Ecology. 2006. V. 87. P. 372-381.

15. Lebl K., Kürbisch K., Bieber C., Ruf T. Energy or information? The role of seed availability for reproductive decisions in edible dormice // J. Comp. Physiol. 2010. V. 180. P. 447-456.

16. Morris P.A., Morris M.J. A 13-year population study of the edible dormouse Glis glis in Britain // Acta Theriologica. 2010. V. 55. P. 279-288.

17. Sailer M., Fietz J. Seasonal differences in the feeding ecology and behavior of male edible dormice (Glis glis) // Mammalian Biology. 2009. V. 74. P. 114124.

18. Fietz J., Pflug M., Schlund W., Tataruch F. Influences of the feeding ecology on body mass and possible implications for reproduction in the edible dormouse (Glis glis) // J. Comp. Physiol. B. 2005. V. 175. P. 45-55.

19. Fietz J., Kager T., Schauer S. Is energy supply the trigger for reproductive activity in male edible dormice (Glis glis)? // J. Comp. Physiol. B. 2009. V. 179. P. 829 837.

20. Формозов А.Н. Об особенностях ареалов русских сонь (Myoxidae) и бурундука (Eutamias asiaticus) // Бюлл. Моск. об-ва испыт. прир. 1928. Вып. 3-4. C. $189-290$.

21. Огнев С.И. Звери СССР и прилежащих стран. Т. 5. М.-Л, 1947. 809 c.

22. Айрапетьянц А.Э. Сони. Л.: Изд-во Ленингр. ун-та, 1983. 192 с.

23. Лозан М.Н. Сони Юго-Запада СССР. Кишинев: Штиница, 1991. 146 с.

24. Ivashkina V.A. Abundance and activity of the edible dormouse (Glis glis Linnaeus, 1766) in the Zhiguli Mountains (Russia, Middle Volga Region) // Polish J. Ecol. 2006. V. 54 (3). P. 337-344.

25. Pilats V. The fat dormouse (Glis glis) in Gauja National Park - the most northern locality within the species' distribution range? // Acta Zoologica Academiae Scientarium Hungaricae. 2003. V. 49. P. 131-137.

26. Juškaitis R., Augutè V. The fat dormouse, Glis glis, in Lithuania: living outside the range of the European beech, Fagus sylvatica // Folia Zool. 2015. V. 64 (4). P. 310-315.

27. Juškaitis R., Baltrūnaite L., Augutè V. Diet of the fat dormouse (Glis glis) on the northern periphery of its distributional range // Mamm. Res. 2015. V. 60. P. 155161.

28. Ивантер Э.В. Периферические популяции эволюционные форпосты вида // Мат-лы конференции «Современные проблемы биологической эволюции». 2007. С. 64.

\section{REPRODUCTIVE ACTIVITY OF MALE EDIBLE DORMICE (GLIS GLIS L., 1766) IN THE PERIPHERAL POPULATION}

(C) 2016

V.A. Vekhnik, candidate of biological sciences, researcher I.I. Sprygin Zhiguli State Nature Biosphere Reserve, Zhigulyovsk (Russia)

Abstract. The edible dormouse is a dendrobiont hibernating rodent breeding once a year. A peculiarity of the species biology is regular reproduction failure in non-mast years. In the center of the area it occurs due to the lack of male reproductive activity. In the studied population on the eastern periphery of the dormouse area previous studies proved the decisive role of mass resorption of embryos at females in the process. The dynamics of males reproductive activity and its impact on the reproduction were not considered previously in detail. In this work the periodicity and intensity of reproductive activity of males, depending on the age and phase of population cycle, was studied. Reproductive activity of the overwhelming majority of males was annually observed, the proportion of individuals not involved in reproduction did not exceed $6,7 \%$. The age differences in the timing of beginning of the reproduction were revealed: yearlings came the first in the activity state and after them two-year and three-year and older individuals became active. The minimal duration of the mating period was observed in yearling males, the maximal - in two-year, which were also characterized by the longest individual periods of reproductive activity. As a result of sharp fluctuations in the population age structure two-year males are the most important group in reproduction, but the three-year and older individuals in mast years are also able to ensure the reproduction of the population. The characteristic feature of reproduction was noted at yearling males: they began reproduction depending on body weight. Fluctuations in the male reproductive activity during the active period do not play a significant role in the regulation of reproduction. Shorter duration of reproductive activity of yearling animals in the years of reproduction failure is compensated by the later beginning of reproduction of three-year and older individuals. Nonsynchronous participation in breeding of males of different age groups provides the involvement in reproduction of maximal number of animals.

Keywords: the edible dormouse; Glis glis; males reproductive activity; mass resorption; breeding; reproduction failure; Zhiguli Mountains; peripheral population; age structure. 